\title{
THE RELATION OF LEFT VENTRICULAR DIASTOLIC DYSFUNCTION AND INCREASED LEFT VENTRICULAR MASS WITH BLOOD PRESSURE VARIABILITY IN NON-ESTABLISHED HYPERTENSIVE PATIENTS
}

\author{
By \\ Moataz Abd Al-Rahman Abd Al-Salam Farag ${ }^{1 * a n d ~ M o h s e n ~ A l i ~}$ \\ Mahmoud Salama ${ }^{2}$ and Yasser El-Sayed Mohammed Hasan ${ }^{2 *}$ \\ ${ }^{1}$ Department of Cardiology, Matrouh specialized Cardiothoracic and Interventional \\ Catheterization Center \\ ${ }^{2}$ Department of Cardiology, Faculty of Medicine, Al-Azhar University, Egypt \\ *Corresponding author: Moataz Abd Al-Rahman Abd Al-Salam Farag, \\ Mobile: (+20)01007859945, E-mail: muataz.7farag@gmail.com
}

\begin{abstract}
Background: Long term high blood pressure is a major risk factor for coronary artery disease, stroke, heart failure, peripheral vascular disease, vision loss and chronic kidney disease.

Objective: To demonstrate the relation between left ventricular diastolic dysfunction increased left ventricular mass and ambulatory blood pressure recording in subjects not known to be hypertensive.

Patients and Methods: This was a- cross sectional study that carried out on (100) normotensive patients in Cardiology Department Clinic at Matrouh Specialized Cardiothoracic and Interventional Catheterization Center from October, 2017 to January 2019.

Results: there was a-significantly marked difference in left ventricular (LV) mass between two groups (normal blood pressure and latent hypertension) and significantly marked difference in diastolic dysfunction. According to normal circadian and impaired circadian, there was a- significant difference between the two major groups in sex, where male >female, and marked difference in LV mass between the two groups (normal circadian and impaired circadian), and in smoking.

Conclusion: Ambulatory blood pressure (AMBP) played an important role as a predictor to estimate prevalence of hypertension based on diastolic dysfunction and increased left ventricular mass in persons with normal blood pressure measures at office specially masked hypertension in white coat hypertensive patients.
\end{abstract}

Keywords: Left ventricular diastolic, blood pressure variability.

\section{INTRODUCTION}

Hypertension determines an increased risk of cardiovascular events which may be predicted by the occurrence of hypertension mediated -organ damage (HMOD) (Sadurska et al., 2012).
In addition to elevated mean levels of blood pressure (BP), short-term daytime or 24-h BP variability (BPV) has been shown to carry an independent prognostic value in hypertensive patients and is 
directly related to HMOD (Park et al., 2020).

Moreover, whenever present, left ventricular dysfunction in hypertension, even if asymptomatic is a potent predictor of adverse cardiovascular events ( $D e$ Simone et al., 2010).

With the growing acknowledgement of the importance of BPV, in its different components, as a possible new cardiovascular risk factor in hypertensive patients, we hypothesized its role in predicting subclinical left ventricular systolic dysfunction in newly diagnosed, never treated hypertensive patients, by focusing in our study on short-term BP variations occurring over a 24 -h period or selectively only during the daytime sub period (Webb et al., 2010).

Ambulatory BP become important tools for diagnosis of hypertension in pre hypertensive stage, white-coat or isolated clinic hypertension currently defines individuals whose blood pressure (BP) is elevated in the medical setting, but normal when assessed away from the medical environment, such as by24-h ambulatory $\mathrm{BP}$ recording and/or home BP measurement (Parati et al., 2020).

High normal blood pressure is defined as systolic blood pressure 130-139 mmhg and/or diastolic blood pressure 8089mmhg. (Mancia et al., 2013).

The aim of this study was to demonstrate the relation between left ventricular diastolic dysfunction, increased left ventricular mass and ambulatory blood pressure recording in subjects not known to be hypertensive.

\section{PATIENTS AND METHODS}

This was a-cross sectional study that carried out on 100 normotensive patients in Cardiology Department Clinic at Matrouh Specialized Cardiothoracic and Interventional Catheterization Center from October, 2017 to January 2019.

The ethics committee of Al-AZHAR University of Medical Sciences approved the study, and written informed consent was obtained from each patient after thorough explanation of the study to patients before enrollment.

\section{Inclusion criteria:}

1. Age: $\geq 18$ years.

2. Sex: both sexes.

3. High normal blood pressure where systolic Bp 130-139mmhg and/or diastolic BP 85-89 mmhg by conventional blood pressure and left ventricular diastolic dysfunction and increased left ventricular mass.

\section{Exclusion criteria:}

1. Any patient with blood pressure $>$ 140/90 mm Hg.

2. Patients on current antihypertensive medication.

3. Patients with diabetes.

4. Renal dysfunction (serum creatinine $\geq$ $2 \mathrm{mg} / \mathrm{dl}$ or macro albuminuria $\geq 300$ $\mathrm{mg} / 24 \mathrm{~h}$ ).

5. Significant valvular or pericardial disease.

6. Heart failure.

7. Coronary heart disease.

8. Previous stroke. 
9. Rhythm disturbances interfere with assessment of echocardiographic finding (e.g. right or left bundlebranch block and atrial fibrillation)

10. Patients with night-time working habits.

11. Patients with already depressed left ventricular ejection fraction (LVEF) $(<55 \%)$.

\section{Each included patient was subjected to:}

Full history taking about the presence of traditional risk factors, including a family history of hypertension, tobacco smoking, coffee or alcohol consumption, and lack of physical activity (defined as aerobic exercise on an All of participants had normal blood.

1. Glucose, chest X ray and Lipid profile as regard in table (3). Regular basis three to four times per week and thorough clinical examination: general and systematic examination and had Conventional office blood pressure measurement.

2. Routine 12 leads ECG to diagnose any arrhythmia, IHD and evidence of chamber enlargement.

3. Chest $\mathrm{X}$ ray to exclude cardiomegaly.

4. Routine laboratory tests.

5. Body mass index was calculated according to formula $\mathrm{BMI}=$ [wight $(\mathrm{kg}) \backslash$ height $(\mathrm{m})]^{2}$.

6. Trans thoracic echocardiography (TTE): Using a commercially available echo-cardio graphic instrument (Vivid S5, Vivid S6, GE Medical Systems) according to the recommendations of the American Society of echocardiography ASE (Armstrong et al., 2012) to measure:

- Left ventricular internal dimensions (LVID).

- Left ventricular ejection fraction by two dimensional echocardiographs (LVEF).

- Diastolic function indices (DFI) including: pulsed wave at mitral valve leaflets, (E/A), tissue Doppler at base of septal mitral leaflet, Em, $\mathrm{E} / \mathrm{Em}$ and LA diameter.

- Left ventricular mass(LVM): Original calculations from Troy and coworkers were the first to be recommended as standard to estimate LV mass from M-mode Measurements, Formula was used according to Foppa et al . (2005).

7. Twenty-four-hour ambulatory BP monitoring (ABPM). A $24 \mathrm{~h}$ ABPM. Based on the ABPMs (TONOPORT V, GE Medical Systems) a portable blood pressure measuring device, we analyzed average $24 \mathrm{~h}$ systolic and diastolic blood pressure (BP), average daytime (6 a.m.-10 p.m.) and nighttime (10 p.m.-6 a.m.) systolic and diastolic $\mathrm{BP}$ and the number of dipper or nondipper patients according to the recommendations of ESC guidelines, AMBPM parameters.

\section{Statistical analysis:}

Data were fed to the computer and analyzed using IBM SPSS software package version 20.0. (Armonk, NY: IBM Corp) Qualitative data were described using number and percent. The Kolmogorov-Smirnov test was used to verify the normality of distribution 
Quantitative data were described using range (minimum and maximum), mean, standard deviation and median. Significance of the obtained results was judged at the $5 \%$ level. Chicago, Illinois, USA).

\section{The following tests were done:}

- Independent-samples t-test of significance was used when comparing between two means.
- Chi-square (x2) test of significance was used in order to compare proportions between two qualitative parameters.

- Mann Whitney-U test

- The confidence interval was set to $95 \%$ and the margin of error accepted was set to $5 \%$. The p-value was considered significant as the following:

\section{RESULTS}

We enrolled a consecutive subset of 100 patients.

According to demographic distribution we enrolled consecutive subset of 100 patients (66 male, $66 \%$ and 34 female, $34 \%$ ), with a mean age of $41.74 \pm 10.77$ years.

Their height ranged from 159-190 cm, with mean of $170.9 \pm 7.13 \mathrm{~cm}$ and weight of $(969-115 \mathrm{~kg})$ with mean of $86.36 \pm 9.11$ $\mathrm{kg}$, body mass index BMI ranged from $(23.30-35.50 \mathrm{~kg} \backslash \mathrm{m} 2$ with mean of $(29.55 \pm 2.5 \mathrm{~kg} \backslash \mathrm{m} 2$.

All of participants had normal blood Glucose, chest $\mathrm{x}$ ray and Lipid profile (Table 1).

Table (1): Distribution of the studied cases according to demographics data $(n=100)$

\begin{tabular}{|c|c|c|}
\hline & Mean \pm SD. & Mean \pm SD. \\
\hline Height $(\mathbf{c m})$ & $170.9 \pm 7.13$ & \\
\hline Weight $(\mathbf{k g})$ & $86.36 \pm 9.11$ & \\
\hline BMI $\left(\mathbf{k g} / \mathbf{m}^{\mathbf{2}}\right)$ & $29.55 \pm 2.55$ & \\
\hline & No. & \% \\
\hline Blood glucose / HA1C & 100 & 100.0 \\
\hline Lipid profile & 100 & 100.0 \\
\hline Chest X ray & 100 & 100.0 \\
\hline & No & $\%$ \\
\hline Gender & Male & 66 \\
\hline Age (years) & Female & 34 \\
\hline & $\leq 40$ & 46 \\
\hline & $>40$ & 54 \\
\hline Age (years) & Min. - Max. & $18.0-61.0$ \\
\hline & Median & 41.50 \\
\hline
\end{tabular}


According to their Echocardiographic data their left ventricular masses were between 120.0 - $440 \mathrm{gm}$ with a mean of $194.4 \pm 73 \mathrm{gm}$. Left ventricular internal diastolic dimension (LVIDD) ranged from $34.0-59 \mathrm{~mm}$ with a mean of $47.24 \pm 6 \mathrm{~g}$.
E\A (m\sec): $(0.61-2.20)$ with mean $(1.01 \pm 0.31)$, Estimated PASP: $(\mathrm{mmHg})$ 15.0 - 44with mean $(24.22 \pm 5)$ and Left atrial L.A diameter ranged from (23$43 \mathrm{~mm}$ with a mean of $(32.95 \pm 4.87)$ and (Ele'):(4.67 - 17.70) with mean(8.53 \pm 2.50), (Table 2).

Table (2): Descriptive analysis of the studied cases according to different echo parameters $(\mathbf{n}=\mathbf{1 0 0})$

\begin{tabular}{|c|c|}
\hline Echo & Mean \pm SD. \\
\hline LV Mass(gm) & $194.4 \pm 73.39$ \\
\hline LVIDD(mm) & $47.24 \pm 6.0$ \\
\hline E\A (m\sec) & $1.01 \pm 0.31$ \\
\hline Estimated PASP (mmHg) & $24.22 \pm 5.84$ \\
\hline Ele` & $8.53 \pm 2.50$ \\
\hline LA diameter $\backslash \mathbf{m m}$ & $32.95 \pm 4.87$ \\
\hline
\end{tabular}

In present study age, sex and smoking were significantly different between the two major groups (normal blood pressure and latent hypertension, (Table 3).
On comparing the two groups according the circadian rhythm, there was a significant difference only in ambulatory results (Table 4). 
Table (3): Comparison between normal and latent groups according to ambulatory result $(n=100)$

\begin{tabular}{|c|c|c|c|c|c|}
\hline \multirow{2}{*}{ Ambulatory result $\quad$ Parameter } & \multicolumn{2}{|c|}{$\begin{array}{l}\text { Normal } \\
(\mathrm{n}=54)\end{array}$} & \multicolumn{2}{|c|}{$\begin{array}{c}\text { Latent } \\
(\mathrm{n}=46)\end{array}$} & \multirow{2}{*}{$\mathbf{p}$} \\
\hline & No. & $\%$ & No. & $\%$ & \\
\hline \multicolumn{6}{|l|}{ Gender } \\
\hline Male & 26 & 48.1 & 40 & 87.0 & \multirow{2}{*}{$<0.001$} \\
\hline Female & 28 & 51.9 & 6 & 13.0 & \\
\hline \multicolumn{6}{|l|}{ Age } \\
\hline Min. - Max. & \multicolumn{2}{|c|}{$18.0-61.0$} & \multicolumn{2}{|c|}{$32.0-58.0$} & \multirow{3}{*}{$<0.001$} \\
\hline Mean \pm SD & \multicolumn{2}{|c|}{$38.41 \pm 11.51$} & \multicolumn{2}{|c|}{$45.65 \pm 8.37$} & \\
\hline Median & \multicolumn{2}{|c|}{37.0} & \multicolumn{2}{|c|}{45.0} & \\
\hline \multicolumn{6}{|l|}{ Smoking } \\
\hline Non smoker & 43 & 79.6 & 19 & 41.3 & \multirow{2}{*}{$<0.001$} \\
\hline Smoker & 11 & 20.4 & 27 & 58.7 & \\
\hline \multicolumn{6}{|l|}{ Diastolic Dysfunction } \\
\hline Grade I & 40 & 74.1 & 18 & 39.1 & \multirow{2}{*}{$<0.001$} \\
\hline Grade II & 14 & 25.9 & 28 & 60.9 & \\
\hline \multicolumn{6}{|l|}{ BMI } \\
\hline Min. - Max. & \multicolumn{2}{|c|}{$23.30-32.60$} & \multicolumn{2}{|c|}{$26.90-35.50$} & \multirow{3}{*}{0.005} \\
\hline Mean \pm SD & \multicolumn{2}{|c|}{$28.90 \pm 2.55$} & \multicolumn{2}{|c|}{$30.32 \pm 2.35$} & \\
\hline Median & \multicolumn{2}{|c|}{29.50} & \multicolumn{2}{|c|}{29.50} & \\
\hline \multicolumn{6}{|l|}{ LV Mass (gm) } \\
\hline Min. - Max. & \multicolumn{2}{|c|}{$119.97-439.96$} & \multicolumn{2}{|c|}{$126.78-439.96$} & \\
\hline Mean \pm SD & 188.2 & 78.14 & 201.5 & $=67.53$ & 0.042 \\
\hline Median & & & & & \\
\hline L.A volume Ele` & & & & & \\
\hline Min. - Max. & 4.64 & 7.70 & 5.11 & 14.60 & \\
\hline Mean \pm SD & 8.60 & 2.78 & 8.4 & 2.15 & 0.961 \\
\hline Median & & & & & \\
\hline LA diameter Imm & & & & & \\
\hline Min. - Max. & 23.1 & 40.0 & 25. & 43.0 & \\
\hline Mean \pm SD & 32.1 & 4.42 & 33.8 & $=5.27$ & 0.094 \\
\hline Median & & & & & \\
\hline Circadian rhythm & & & & & \\
\hline Normal & 24 & 63.0 & 15 & 32.6 & \\
\hline Impaired circadian rhythm & 20 & 37.0 & 31 & 67.4 & 0.002 \\
\hline
\end{tabular}

$\chi 2$ : Chi square test, $\mathrm{t}$ : Student t-test, U: Mann Whitney test, $\mathrm{p}: \mathrm{p}$ value for comparing between normal and latent 
THE RELATION OF LEFT VENTRICULAR DIASTOLIC...

Table (4): Comparison between normal and impaired circadian groups $(n=100)$

\begin{tabular}{|c|c|c|c|c|c|}
\hline \multirow[t]{2}{*}{$\begin{array}{l}\text { Circadian rhythm } \\
\text { parameter }\end{array}$} & \multicolumn{2}{|c|}{$\begin{array}{l}\text { Normal } \\
(n=49)\end{array}$} & \multicolumn{2}{|c|}{$\begin{array}{l}\text { Impaired circadian } \\
\text { rhythm }(n=51)\end{array}$} & \multirow[t]{2}{*}{$\mathbf{P}$} \\
\hline & No. & $\%$ & No. & $\%$ & \\
\hline Gender & & & $\mathrm{bmm}$ & & \\
\hline Male & 29 & 59.2 & 37 & 72.5 & \multirow{2}{*}{0.158} \\
\hline Female & 20 & 40.8 & 14 & 27.5 & \\
\hline \multicolumn{6}{|l|}{ Age } \\
\hline Min. - Max. & \multicolumn{2}{|c|}{$18.0-58.0$} & \multicolumn{2}{|c|}{$25.0-61.0$} & \multirow{3}{*}{0.843} \\
\hline Mean \pm SD & \multicolumn{2}{|c|}{$41.96 \pm 10.88$} & \multicolumn{2}{|c|}{$41.53 \pm 10.76$} & \\
\hline Median & \multicolumn{2}{|c|}{42.0} & \multicolumn{2}{|c|}{41.0} & \\
\hline \multicolumn{6}{|l|}{ Smoking } \\
\hline Non smoker & 36 & 73.5 & 26 & 51.0 & \multirow{2}{*}{0.021} \\
\hline Smoker & 13 & 26.5 & 25 & 49.0 & \\
\hline \multicolumn{6}{|l|}{\begin{tabular}{|l} 
Diastolic Dysfunction \\
\end{tabular}} \\
\hline Grade I & 34 & 69.4 & 24 & 47.1 & \multirow{2}{*}{0.024} \\
\hline Grade II & 15 & 30.6 & 27 & 52.9 & \\
\hline \multicolumn{6}{|l|}{ BMI } \\
\hline Min. - Max. & \multicolumn{2}{|c|}{$24.70-34.10$} & \multicolumn{2}{|c|}{$23.30-35.50$} & \multirow{3}{*}{0.003} \\
\hline Mean \pm SD & \multicolumn{2}{|c|}{$28.80 \pm 2.13$} & \multicolumn{2}{|c|}{$30.28 \pm 2.73$} & \\
\hline Median & \multicolumn{2}{|c|}{29.10} & \multicolumn{2}{|c|}{30.10} & \\
\hline \multicolumn{6}{|l|}{ LA diameter $\backslash \mathrm{mm}$} \\
\hline Min. - Max. & \multicolumn{2}{|c|}{$25.0-40.0$} & \multicolumn{2}{|c|}{$23.0-43.0$} & \multirow{3}{*}{0.697} \\
\hline Mean \pm SD & & .50 & 33. & 5.25 & \\
\hline Median & & & & & \\
\hline LV Mass (gm) & & & & & \\
\hline Min. - Max. & 119. & 34.48 & 121.3 & 39.96 & \\
\hline Mean \pm SD & 172. & 3.69 & 214. & 76.73 & $<0.001$ \\
\hline Median & & & & & \\
\hline L.A volume Ele` & & & & & \\
\hline Min. - Max. & & & 5.1 & 4.60 & \\
\hline Mean \pm SD & & & & 20 & 0.446 \\
\hline Median & & & & & \\
\hline Ambulatory result & & & & & \\
\hline Normal & 34 & 69.4 & 20 & 39.2 & \\
\hline Latent & 15 & 30.6 & 31 & 60.8 & 0.002 \\
\hline
\end{tabular}

$\chi 2$ : Chi square test, $\mathrm{t}$ : Student t-test, $\mathrm{p}: \mathrm{p}$ value for comparing between normal and impaired circadian rhythm

\section{DISCUSSION}

Hypertension (HTN), is a long term medical condition in which the blood pressure in the arteries is persistently elevated (Naish and court 2014). Long term high blood pressure, however, is a major risk factor for coronary artery disease, stroke, heart failure, peripheral vascular disease, vision loss and chronic kidney disease (Lackland et al., 2015).

It can be modified if early diagnosed and if diet and therapy are prescribed. Ambulatory blood pressure monitoring (ABPM) provides important benefits in the management of hypertensive patients as the large number of readings during 
24h offer a clearer assessment than a single measurement and provides a more reliable measure of a patient's BP than isolated clinic measures and is not subjected to the white-coat effect' which can overestimate BP, particularly in susceptible patients.

Average blood pressure (BP) value for 24 hours and average values during day and night time correlated more strongly to cardiovascular morbidity than single office values. Different summary measures of BP from ABPM have been described and all have evidence of prognostic significance for cardiovascular morbidity beyond average value (Grossman et al., 2013).

We assessed the prevalence of blood pressure variability in patients with diastolic dysfunction and increased left ventricular mass. We also aimed to clarify ambulatory predictors and to estimate prevalence of hypertension based on diastolic dysfunction and increased left ventricular mass, this study conducted on 100 normotensive Patients with diastolic dysfunction and increased left ventricular mass).

In our study, we enrolled a consecutive subset of 100 patients (66 male, 66\% and44female, 44\%), their body mass index BMI ranged from (23.30 to 35.50) their Heart rate ranged from (52.0 to 105.)), systolic blood pressure ranged from (100.0 to 139.0), diastolic blood pressure ranged from (70.0 to 89.0) with mean (77.08 \pm 6.35 ) and LV Mass (gm.) ranged from (120.0 to 440).

\section{Our study group consisted were classified as:}

According to the level of average $24 \mathrm{~h}$ ambulatory BP result into: Those had Normal blood pressure (54\%) and those had latent hypertension (46\%).

According to the circadian rhythm into those had normal circadian rhythm were $49 \%$ and those had impaired circadian rhythm been $51 \%$.

In the present study, LA diameter, diastolic function Ele had no difference between the two major groups (normal blood pressure and latent hypertension.

There were marked differences between two groups according to age, gender (sex), smoking and in circadian rhythm there was a marked difference in LV mass between two groups and diastolic dysfunction that was in agreement with De Simone et al. (2011) who showed at least one BP measurement $>140 / 90 \mathrm{mmHg}$ in the year prior to observation. The average age was $48+/$ 11 , without any significant correlation to LVMI. Their results showed LVMI had a significant correlation with systolic BP at ABPM but not with diastolic BP.

Muller et al. (2017) showed that hypertension is associated with LV diastolic dysfunction, and diastolic function is further impaired in the presence of hypertensive LV hypertrophy. Indeed, LV diastolic dysfunction is considered to be an early sign of hypertensive heart disease that was not matching with current study in diastolic BP. This discrepancy between results is partly attributed to the large number of current study ethnical, regional, lifestyle pattern differences and difference of 
subset inclusion criteria; Dipper patients represented $76.3 \%$ of the population, without any difference in LVMI between dippers and non-dippers. Dipper patients had a higher prevalence of normal left ventricles as compared with non-dippers.

There was a significant correlation between LV mass and BMI that was in agreement with Rashid et al. (2014) their results showed that there was linear correlation between BMI and LV mass.

According to circadian rhythm, there was no significant difference between the two major groups in age, sex, LA diameter but there was a significant difference between two groups in LV mass where significant and that was in agreement with Mustafa et al.( 2016). They found that Nocturnal diastolic BP variability estimated as SD had significantly higher values in patients with $\mathrm{LVH}$, night time had higher values in patients with LVH vs. those with normal LV mass, but disagreement with our study that we studied normotensive patients.

Smoking, diastolic dysfunction and ambulatory result where marked significant between two groups and that was in agreement with Zhang et al. (2015) except in gender where female in this study >male this discrepancy between results is partly attributed to ethnical, regional, lifestyle pattern differences.

Quinaglia et al. (2011) showed significant correlation between diastolic dysfunction and dipping of blood pressure.

Normal ambulatory results and circadian rhythm rather than increased $\mathrm{LV}$ mass and diastolic dysfunction may be due to some of participants were athletic, hard worker, obese and majority age above age of 40 .

\section{CONCLUSION}

Left ventricular diastolic dysfunction and increased left ventricular mass is potent predictor of adverse cardiovascular events. Ambulatory blood pressure (AMBP) plays an important role as a predictor to estimate prevalence of hypertension based on diastolic dysfunction and increased left ventricular mass in persons with normal blood pressure measures at office specially masked hypertension in white coat hypertensive patients.

\section{RECOMMENDATION}

1. Multiple cardiology centers sharing in large study.

2. Including patients with renal dysfunction (serum creatinine $\geq 2$ $\mathrm{mg} / \mathrm{dl}$ or macro albuminuria $\geq 300 \mathrm{mg}$ $/ 24 \mathrm{~h}$.

3. Including diabetic patients.

4. Survey of all family members who were diagnosed as hypertensive patient.

5. Survey for all persons with increased body mass index (BMI).

6. Survey for all smoker persons.

\section{REFERENCES}

1. Armstrong, A. C., Gidding, S., Gjesdal, O., Wu, C., Bluemke, D. A., and Lima, J. A (2012): LV mass assessed by echocardiography and CMR, cardiovascular outcomes, and medical practice. JACC: Cardiovascular Imaging, 5(8): 837-848.

2. De Simone, G., Devereux, R. B., Chinali, M., Roman, M. J., Barac, A., Panza, J. A and Howard, B. V. (2011): Sex differences in obesity-related changes in left ventricular 


\section{MOATAZ ABD AL-RAHMAN ABD AL-SALAM et al.,}

morphology: the Strong Heart Study. Journal of hypertension, 29(7), 1431.

3. De Simone, G., Izzo, R., Chinali, M., De Marco, M., Casalnuovo, G., Rozza, F and De Luca, N. (2010): Does information on systolic and diastolic function improve prediction of a cardiovascular event by left ventricular hypertrophy in arterial.

4. Foppa, M., Duncan, B. B., \& Rohde, L. E. (2005): Echocardiography-based left ventricular mass estimation. How should we define hypertrophy? Cardiovascular ultrasound 2005; 3(1): 17.

5. Grossman, E. (2013): Ambulatory blood pressure monitoring in the diagnosis and management of hypertension. Diabetes care, 36(Supplement 2), S307-S311. hypertension?. Hypertension, 56(1), 99-104.

6. Lackland, D. T., \& Weber, M. A. (2015): Global burden of cardiovascular disease and stroke: hypertension at the core. Canadian Journal of Cardiology, 31(5): 569-571.

7. Mustafa, E. R., Istratoaie, O., \& Musetescu, $R$ (2016): Blood pressure variability and left ventricular mass in hypertensive patients. Current health sciences journal, 42(1), 47.

8. Mancia, G., Fagard, R., Narkiewicz, K., Redon, J., Zanchetti, A., Boehm, M and Galderisi, M. (2013): ESH/ESC guidelines for the management of arterial hypertension: the Task Force for the Management of Arterial Hypertension of the European Society of Hypertension (ESH) and of the European Society of Cardiology (ESC). Blood pressure; 22(4): 193-278.

9. Muller-Brunotte R, Kahan T, López B. (2007): Myocardial fibrosis and diastolic dysfunction in patients with hypertension: results from the Swedish Irbesartan Left Ventricular Hypertrophy Investigation versus Atenolol (SILVHIA). J Hypertens, 25(9):1958-66

10. Naish J and Court D S (2014): Medical sciences $(2 \quad$ ed.); p. 562. ISBN 9780702052491,https://www.elsevier.com/bo oks/Medical-Sciences/Naish/978-0-70205138-8.
11. Parati, G. (2020): Ambulatory blood pressure monitoring over $24 \mathrm{~h}$ : A Latin American Society of Hypertension position paper-accessibility, clinical use and cost effectiveness of ABPM in Latin America. Mensarewent, 8-9.

12. Park, C., Rapala, A., Jones, S., Williams, S., Chaturvedi, N., and Hughes, A. (2020): 1.1 Differential Changes in Peripheral and Central Blood Pressure from Adolescence to Adulthood. Artery Research, 25(10), S1-S.

13. Quinaglia, T., Martins, L. C., Figueiredo, V. N., Santos, R. C., Yugar-Toledo, J. C., Martin, J. V., and Moreno, H. (2011): Non-dipping pattern relates to endothelial dysfunction in patients with uncontrolled resistant hypertension. Journal of human Hypereansim -2917): 442-448.

14. Rashid, M. A., Qureshi, B. A., Ahmed, N., and Sherwani, M. A.(2014): Impact of body mass index on left ventricular mass. Journal of Ayub Medical College Abbottabadn 26(2): 167-169.

15. Sadurska, E., Jawniak, R., Majewski, M., and Czekajska-Chehab, E. (2012): Takayasu arteritis as a cause of arterial hypertension. Case report and literature review. European Journal of Pediatrics, 171(5): 863-869.

16. Webb, A. J., Fischer, U., Mehta, Z., and Rothwell, P. M. (2010): Effects of antihypertensive-drug class on inter individual variation in blood pressure and risk of stroke: a systematic review and metaanalysis. The Lancet , 375(9718): 906-

17. Zhang, Y., Kollias, G., Argyris, A. A., Papaioannou, T. G., Tountas, C., Konstantonis, G. D and Protogerou, A. D. (2015): Association of left ventricular diastolic dysfunction with 24-h aortic ambulatory blood pressure: the SAFAR study. Journal of human hypertension, 29(7): 442-448. 


\section{العلاقة بين إعتلال عضلة القلب الاتبساطية وزيادة الكتلة}

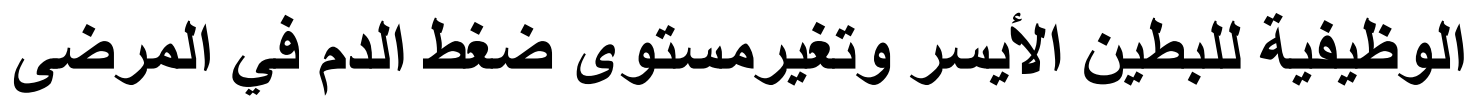

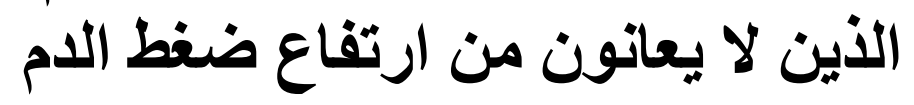

معتز عبد الرحمن عبد السلام فرج، محسن على محمود سلامة، ياسر السيد محمد حسن قسم القلب والأوعية الاموية، طب الأزهر بالقاهرة

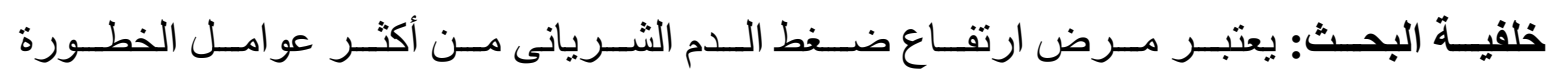

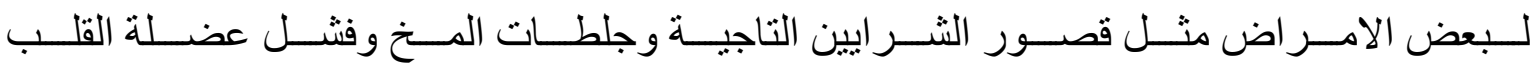
وفقدان البصر وتصلب الثر ايين الطرفية والفشل الكلوى الحاد أو المزمن.

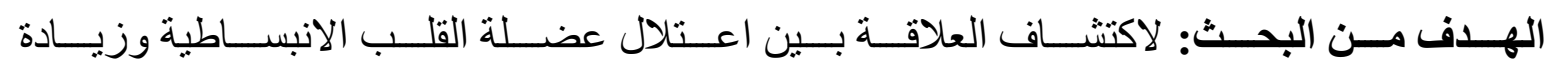

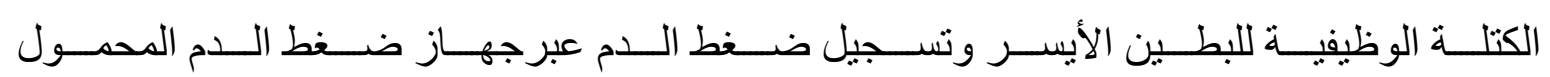
في المرضى الذين لا يعانون من ارتفاع ضغط الدم.

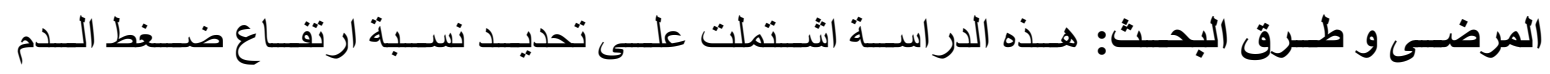

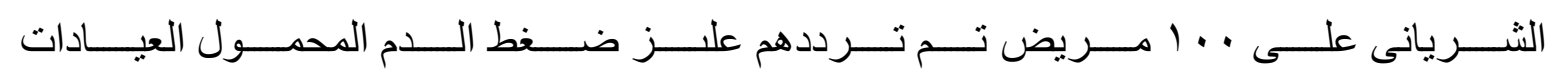

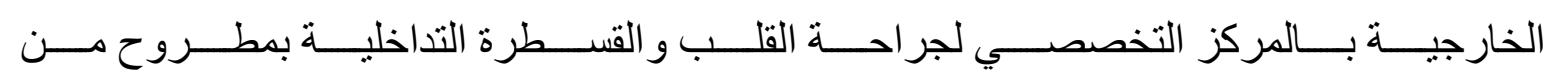

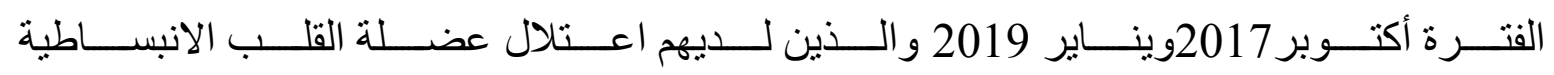
وزيادة الكتلة الوظيفية للبطين الأيسر.

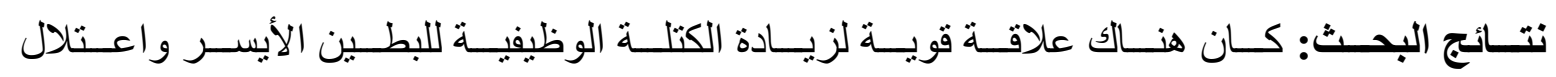

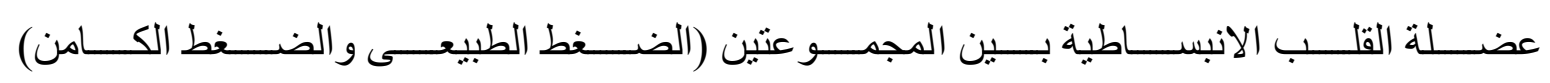

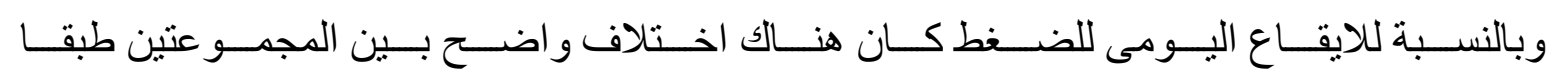

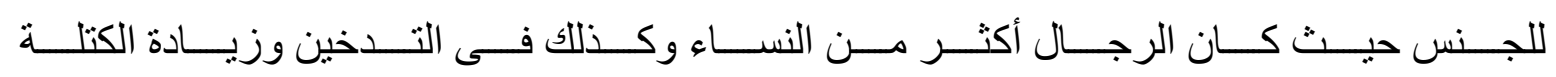

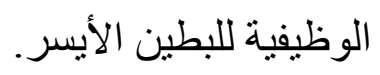

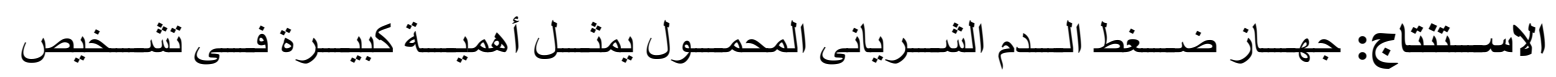

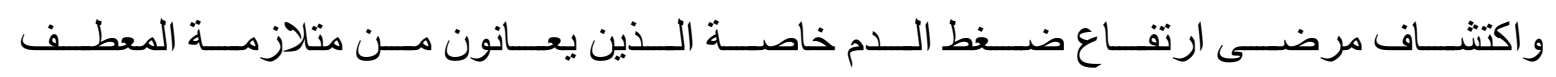
الابيض وحالات الضغط المقنعة. 